\title{
Neuropharmacological characterization of the oneirogenic Mexican plant Calea zacatechichi aqueous extract in mice
}

\author{
Maciej Salaga $^{1} \cdot$ Jakub Fichna $^{1} \cdot$ Katarzyna Socala $^{2} \cdot$ Dorota Nieoczym $^{2}$ • \\ Mateusz Pieróg ${ }^{2} \cdot$ Marta Zielińska $^{1} \cdot$ Anna Kowalczuk $^{3} \cdot$ Piotr Wlaź $^{2}$
}

Received: 3 November 2015 / Accepted: 12 January 2016 / Published online: 28 January 2016

(C) The Author(s) 2016. This article is published with open access at Springerlink.com

\begin{abstract}
This study evaluates the neuropharmacological effects of the aqueous extract of the Mexican plant Calea zacatechichi Schltdl., which is commonly used in folk medicine to treat cough, asthma, and gastrointestinal disorders. Moreover, it has been used for centuries in traditional rituals based on divination and is thought to possess hallucinogenic activity. To test the neuropharmacological effects of the aqueous extract of C. zacatechichi we used mouse models of convulsions, an elevated plus-maze test and measured locomotor activity. We also evaluated the effect of the extract on antidepressant-like behavior in forced swim test, as well as on muscular strength in a grip test. Moreover the antinociceptive action of the extract was evaluated in the hot-plate and writhing tests. The chemical composition of the extract was evaluated using LC-MS techniques. The aqueous extract of C. zacatechichi did not affect any of the parameters measured in seizure models. It had also no influence on anxiety, exploratory behavior and muscular strength in the applied doses. On the other hand, the extract exhibited antinociceptive effect in the mouse model of abdominal pain. Chemical characterization of the extract showed the presence of chlorogenic acid, acacetin, and germacranolides. Based on this report we suggest that aqueous extract of $C$. zacatechich $i$
\end{abstract}

Maciej Sałaga and Jakub Fichna have an equal contribution to this paper.

Piotr Wlaź

piotr.wlaz@umcs.lublin.pl

1 Department of Biochemistry, Faculty of Medicine, Medical University of Lodz, Łódź, Poland

2 Department of Animal Physiology, Institute of Biology and Biochemistry, Maria Curie-Sklodowska University, Akademicka 19, 20-033 Lublin, PL, Poland

3 National Medicines Institute, Warsaw, Poland has insignificant neuropharmacological effects in vivo and reduces abdominal pain perception. Our results, together with previous studies showing beneficial effects of the extracts obtained from $C$. zacatechichi suggest that these preparations may be used to treat medical conditions.

Keywords Anticonvulsant activity · Seizure threshold . Abdominal pain $\cdot$ Mice

\section{Introduction}

Calea zacatechichi Schltdl. (Asteraceae alt. Compositae) is a Latin-American plant, also known as Dream Herb or Bitter Grass, which grows predominantly in south-eastern Mexico. Native Indian tribes have used it for centuries as a remedy for cough and asthma, as well as gastrointestinal (GI) tract disorders, such as stomach-ache and diarrhea (Leonti et al. 2003). To date, several scientific reports have shown beneficial effects of C. zacatechichi extracts. For example, $\mathrm{Wu}$ et al. (2011) characterized anti-microbial and anti-leishmanial activity of compounds isolated from C. zacatechichi. VenegasFlores et al. (2002) reported anti-inflammatory properties of C. zacatechichi aqueous extract. Furthermore, Bork et al. (1997) demonstrated that $C$. zacatechichi leaves extract negatively interfered with activation of Nf-kB transcriptional factor. Most recently, Sałaga et al. (2015) showed that dichloromethane extract of C. zacatechichi has anti-diarrheal and antinociceptive effects in the GI tract.

Apart from its medicinal properties, C. zacatechichi is also known to have some central nervous system (CNS)-related effects. Several Indian tribes, such as Chontal Indians used $C$. zacatechichi for rituals aimed at dream-based divination (Wu et al. 2011). In line, it has been reported that C. zacatechichi has some hallucinogenic properties and may affect sleep. Its 
organic extracts induce somnolence-like behaviors accompanied by the changes in EEG and light sleep in cats (Mayagoitia et al. 1986). Large doses elicit salivation, ataxia and retching (Mayagoitia et al. 1986). A double-blind human study by Mayagoitia et al. demonstrated that in healthy volunteers, low doses of C. zacatechichi extracts increased reaction time and time-lapse estimation (Mayagoitia et al. 1986). Moreover, it has been shown that the effects of the plant upon cingulum discharge frequency were significantly different from other hallucinogenic drugs, such as ketamine, quipazine and phencyclidine (Mayagoitia et al. 1986). In the light of the currently available scientific literature it is difficult to estimate whether therapeutic effects of $C$. zacatechichi extracts would be affected by CNS-related effects and, if any, which types of extracts are particularly abundant in hallucinogenic compounds. To shed light on the neuropsychopharmacological profile of the plant and its constituents, we investigated the effect of C. zacatechichi aqueous extract on seizure threshold, muscular strength, mood-related symptoms and locomotor activity in mice. Furthermore we assessed the antinociceptive properties of the extract in models of centrally- and peripherally-mediated antinociception. We also characterized the chemical composition of the extract by mass spectrometry to find novel biologically active compounds responsible for its potential effects.

\section{Materials and methods}

\section{Plant material}

Dried shredded herb of Calea zacatechichi (leaves, stems and flowers) was purchased from the company Maya Ethnobotanicals (Haarlem, Netherlands). The material originated from Mexico according to the provider declaration. The authenticity of the purchased material was confirmed through the macroscopic and microscopic assessment which was carried out in comparison to the authenticated C. zacatechichi material from Daniel Siebert, provided by The University of Mississippi School of Pharmacy, Mississippi, MS, USA. The plant name has been checked with http://www.theplantlist.org on 30-102013.

\section{Extract preparation}

Powdered C. zacatechichi herb $(150 \mathrm{~g})$ was extracted 4 times with 21 of boiling water. The aqueous solution was filtered and lyophilized. C. zacatechichi aqueous extract was prepared in the National Medicines Institute, Warsaw, Poland.

\section{Animals}

Experimentally naïve, age matched male albino Swiss mice (Laboratory Animals Breeding, Słaboszów, Poland) weighing
22-30 g were used in all experiments. The animals were housed in Makrolon cages under strictly controlled laboratory conditions $\left(22-23{ }^{\circ} \mathrm{C}\right.$, relative humidity, $45-55 \%, 12 \mathrm{~h}$ light/ dark cycle, lights on at 6:00 a.m.). Chow pellets (Agropol S.J., Motycz, Poland) and tap water were available ad libitum. After at least 7 days of acclimatization, experiments were performed between 8:00 and 16:00 h to minimize circadian influences. Each animal was used only once. The experimental protocol was in accordance to the European Communities Council Directive of 22 September 2010 (2010/63/EU) and Polish legislation acts concerning animal experimentations and was approved by the Local Ethics Committee at the Medical University of Lublin (license number 45/2013).

\section{Drug administration}

All drugs and reagents, unless stated otherwise, were purchased from Sigma-Aldrich (Poznań, Poland). The C. zacatechichi aqueous extract (powder) was diluted in saline to desired concentrations and administered orally (p.o.) by gastric gavage in a volume of $10 \mathrm{ml} / \mathrm{kg} 60 \mathrm{~min}$ before the respective test. In time course experiments the $C$. zacatechichi extract was administered p.o. 15, 30, 60, 120 and $240 \mathrm{~min}$ before the test. Control animals received saline alone (p.o.). The vehicles in the used concentrations had no effects on the observed parameters. The dilutions of the C. zacatechichi extract used in this study were chosen based on preliminary experiments, in reference to doses used in humans.

\section{Maximal electroshock seizure threshold (MEST) test in mice}

The electroshock seizures were induced by sine-wave alternating current (maximal output voltage $500 \mathrm{~V}, 50 \mathrm{~Hz}$ for $0.2 \mathrm{~s}$ ) applied via transcorneal electrodes. The current was delivered by a rodent shocker (type 221; Hugo Sachs Elektronik, Freiburg, Germany). An ocular anesthetic (1\% solution of tetracaine hydrochloride) was applied into each eye $1 \mathrm{~min}$ before stimulation to minimize the pain. Transcorneal electrodes were soaked in $0.9 \%$ saline to maximize the conductance. During stimulation mice were manually immobilized and immediately after the stimulation they were placed in a Plexiglas arena $(37 \mathrm{~cm} \times 21 \mathrm{~cm} \times 14 \mathrm{~cm})$ for behavioral observation. The presence or absence of seizure activity was recorded. Tonic hindlimb extension was taken as an endpoint.

The thresholds for maximal electroconvulsions were assessed by the 'up-and-down' method described by Kimball et al. (1957). In this method, current intensity was lowered or raised by $0.06-\log$ intervals depending on whether the previously stimulated animal did or did not exert seizure activity, respectively. Each mouse was stimulated only once at any given current intensity. Experimental groups comprised 18-20 animals. Obtained data was used to determine the threshold current 
causing an endpoint in $50 \%$ of mice $\left(\mathrm{CC}_{50}\right.$ with confidence limits for $95 \%$ probability). For further methodological detail see: Giardina and Gasior (2009).

\section{The $6 \mathrm{~Hz}$ psychomotor seizure threshold test in mice}

The psychomotor seizure thresholds were examined using square-wave alternating current stimuli $(0.2-\mathrm{ms}$ duration pulses at $6 \mathrm{~Hz}$ for $3 \mathrm{~s}$ ) delivered via saline-soaked corneal electrodes by a Grass S48 stimulator coupled with a constant current unit CCU1 (both from Grass Technologies, West Warwick, RI, USA). Ocular anesthesia and observation arena were made as described in above section. The seizures induced by $6 \mathrm{~Hz}$ stimulation were characterized by immobility or stun posture, which was frequently followed by rearing, forelimb clonus, twitching of the vibrissae and elevated or Straub tail (Barton et al. 2001; Barton et al. 2003). Renewal of normal exploratory behavior or the absence of the features listed above within $10 \mathrm{~s}$ after stimulation were considered as the lack of seizures. The 'up-and-down' method described by Kimball et al. (1957) was used in order to choose the current intensity. Data obtained in groups of 19-20 animals were used to determine the threshold current causing $6 \mathrm{~Hz}$-induced seizures in $50 \%$ of mice $\left(\mathrm{CC}_{50}\right.$ with confidence limits for $95 \%$ probability).

\section{The intravenous pentylenetetrazole (PTZ) seizure threshold test in mice}

Briefly, mice were placed in a cylindrical plastic restrainer (12-cm long, 3-cm inner diameter) and a 27-gauge needle (Sterican ${ }^{\circledR}$, B. Braun Melsungen, Melsungen, Germany) was inserted into the lateral tail vein. The needle was attached by polyethylene tubing (PE20RW, Plastics One Inc., Roanoke, VA, USA) to a plastic syringe, which was mounted in a syringe pump (model Physio 22, Hugo Sachs ElektronikHarvard Apparatus GmbH, March-Hugstetten, Germany). The correct needle placement in the tail vein was verified by the appearance of blood in the tubing. The $1 \%$ aqueous solution of PTZ, was administered into the lateral tail vein of unrestrained animals at a constant rate of $0.2 \mathrm{ml} / \mathrm{min}$. Endpoints recorded to determine seizure thresholds: (1) the initial myoclonic twitch, (2) the onset generalized clonus with loss of righting reflex and (3) the onset of tonic forelimb extension. The time elapsed from the start of PTZ infusion to the onset of all three seizure stages was measured. The thresholds were calculated separately for each endpoint according to the formula: threshold dose of PTZ $(\mathrm{mg} / \mathrm{kg})=$ (infusion duration $(\mathrm{s}) \times$ infusion rate $(\mathrm{ml} / \mathrm{s}) \times \mathrm{PTZ}$ concentration $(\mathrm{mg} /$ $\mathrm{ml}) \times 1000) /$ body weight $(\mathrm{kg})$. Seizure thresholds were expressed as the amount of PTZ $(\mathrm{mg} / \mathrm{kg}) \pm \mathrm{SEM}$ needed to produce the first sign of each endpoint in groups of 10-14 mice.

\section{Forced swim test}

Forced swim test was performed according to the modified method of Porsolt et al. (1977). Mice (10-12/group) were individually placed into the glass cylinders (height $25 \mathrm{~cm}$, diameter $10 \mathrm{~cm}$ ) containing $10 \mathrm{~cm}$ of water maintained at $23-25^{\circ} \mathrm{C}$ and left in it for $6 \mathrm{~min}$. The total duration of immobility was recorded during the last 4 min of the 6-min testing period. The mice were considered immobile when they remained floating motionless in the water, making only the slow movements necessary to keep their heads above the water.

\section{Elevated plus-maze test}

To identify anxiolytic properties of the studied extract we used elevated plus-maze test in mice, as described earlier by Lister (1987). The plus-maze apparatus was made of black polyvinyl chloride and consisted of two open $(30 \times 5 \mathrm{~cm})$ and two enclosed $(30 \times 5 \times 15 \mathrm{~cm})$ arms. The arms extended from a central platform of $5 \times 5 \mathrm{~cm}$. The apparatus was mounted $38 \mathrm{~cm}$ above the floor level and was illuminated by red light. Animals (12 mice per group) were placed in the center of the apparatus (facing an enclosed arm), allowed to freely explore the maze and observed for $5 \mathrm{~min}$. The following parameters were recorded: total number of arm entries, number of entries into the open arms and the time spent in these arms. An entry was defined as crossing the boundaries of the arms with all four paws. The percentage of entries and time spent in the open arms were calculated.

\section{The grip-strength test in mice}

The effect of the studied extract on skeletal muscle strength in mice was measured in the grip-strength test, as described before (Nieoczym et al. 2010). The grip-strength apparatus (BioSeb, Chaville, France) consisted of a steel wire grid $(8 \times 8 \mathrm{~cm})$ connected to an isometric force transducer. Animals (12 mice/group) were lifted by the tail so that they could grasp the grid with their forepaws. Then animals were pulled backward gently by the tail until they released the grid. The maximal grip strength value (in newtons, $\mathrm{N}$ ) of the animal was recorded. The procedure was repeated three times and the mean force exerted by each mouse was recorded. The mean force was normalized to body weight and expressed in $\mathrm{N} / \mathrm{g}$.

\section{Locomotor activity}

To monitor the spontaneous locomotor activity of mice, an IR Actimeter system (Panlab/Harvard Apparatus, Barcelona, Spain) was used. This consisted of a square arena surrounded by a $25 \times 25 \mathrm{~cm}$ frame, containing a total of $16 \times 16$ infrared 
beams located on the sides and spaced at $1.5 \mathrm{~cm}$ intervals. Mice (11 per group) pretreated with C. zacatechichi aqueous extract or vehicle were placed individually in the actimeter and allowed to freely explore the arena for $6 \mathrm{~min}$. The number of crosses of the infrared beams was counted by the device within last $4 \mathrm{~min}$ of the test, what corresponds to the time interval analyzed in the forced swim test.

\section{Behavioral pain responses}

\section{Hot-plate test}

The hot-plate test was performed according to the method described earlier (Eddy and Leimbach 1953; Sobczak et al. 2014). A transparent plastic cylinder (14 cm diameter, $20 \mathrm{~cm}$ height) was used to confine the mouse on the heated $\left(55 \pm 0.5^{\circ} \mathrm{C}\right)$ metal plate. Animals (12 mice/group) were administered with vehicle or C. zacatechichi aqueous extract $(200 \mathrm{mg} / \mathrm{kg}$, p.o.) and gently placed on the hot-plate. The latencies to paw licking, rearing and jumping were measured. A cut-off time of $240 \mathrm{~s}$ was used to avoid thermal skin injury. The dose of $200 \mathrm{mg} / \mathrm{kg}$ used in behavioral pain tests was selected, as the lowest from the doses tested in neuropharmacological tests which did not cause any CNS-related adverse events.

\section{Writhing test}

The writhing test was performed as described earlier (Laird et al. 2001; Sałaga et al. 2014). After administration of vehicle or C. zacatechichi aqueous extract ( $200 \mathrm{mg} / \mathrm{kg}$, p.o.), mice (12 mice/group) were injected intraperitoneally (i.p.) with $0.75 \%$ $(v / \mathrm{v}$ in saline) acetic acid solution $(10 \mathrm{ml} / \mathrm{kg})$. After $5 \mathrm{~min}$ of recovery, mice were placed in individual observational cages and the total number of writhes was counted during three periods of $5 \mathrm{~min}$ each. The writhing response, regarded as a nociceptive behavior, was characterized by elongation of the body and the development of tension in the abdominal muscles and hind paws.

\section{LC-MS method}

A tandem mass spectrometer MicrOTOF-Q II from Bruker Daltonics (Bremen, Germany) coupled with an LC-UV Ultimate 3000 system (Dionex, a part of Thermo Fisher Scientific) was used to obtain the electrospray ionization time-of-flight mass spectra (LC-ESI-MS/MS-TOF). The following settings were used: electrospray ionization (ESI) in the positive ion mode, dry gas (nitrogen) flow rate $8.0 \mathrm{l} / \mathrm{min}$, the dry heater $180^{\circ} \mathrm{C}$, the capillary voltage $4500 \mathrm{~V}$ and end plate offset $-500 \mathrm{~V}$. MS data were recorded in the full scan mode (from 50 to $3000 \mathrm{~m} / \mathrm{z}$ ). Data processing was carried out with Compass 1.3 (Bruker Daltonics).
Chromatographic analysis was performed on a $\mathrm{C}_{18}$ analytical column (Hypersil GOLD, $150 \mathrm{~mm} \times 2.1 \mathrm{~mm} ; 3 \mu \mathrm{m}$ particle size; Thermo Fisher Scientific, Waltham, MA, USA) with a guard column (Hypersil GOLD, $10 \mathrm{~mm} \times 2.1 \mathrm{~mm} ; 3 \mu \mathrm{m}$ particle size; Thermo Fisher Scientific, Walthman, MA, USA). The linear gradient elution was performed using $0.1 \%$ formic acid in solvent A (water/acetonitrile, 9:1, v:v) and $0.1 \%$ formic acid in solvent $B$ (methanol/acetonitrile, 9:1, v:v). An applied linear gradient was as follows: initially $10 \%$ B from 0 to $2 \mathrm{~min}$, then linear gradient to $90 \% \mathrm{~B}$ at $7 \mathrm{~min}$, constant $90 \% \mathrm{~B}$ to $10 \mathrm{~min}$, finally return to $10 \% \mathrm{~B}$ and equilibration for $2 \mathrm{~min}$. The flow rate was $0.15 \mathrm{ml} / \mathrm{min}$ and the injection volume was $2 \mu l$. The analysis was carried out at $25{ }^{\circ} \mathrm{C}$.

To identify individual compounds we analyzed the high resolution mass spectra. TOF analyzer enables a very accurate mass detection and the assignment to the most probable molecular formula. Suggested molecular formulas were accepted when the mass error was below $5 \mathrm{ppm}$. Additionally we enhanced the identification by the analysis of the isotopic pattern of the compounds. When possible, obtained MS/MS spectra were additionally compared with spectra of identified compounds in the METLIN: Metabolite and Tandem MS Database (http://metlin.scripps.edu).

\section{Statistical analysis}

Data obtained from the MEST test and the $6 \mathrm{~Hz}$ seizure threshold test were analyzed according to Kimball et al. (1957) and are presented as $\mathrm{CC}_{50}$ values with $95 \%$ confidence limits. Differences in $\mathrm{CC}_{50}$ values were analyzed by using one-way analysis of variance (ANOVA) followed by Dunnett's post hoc test. All other results are expressed as means \pm SEM and were analyzed by one-way ANOVA followed by Dunnett's post hoc test or Student's $t$ test (locomotor activity). Statistical significance was noted when $p$ values were equal to or less than 0.05 . All statistical calculations were performed with GraphPad Prism version 5.03 for Windows (GraphPad Software, San Diego, CA, USA).

\section{Results}

\section{Aqueous extract of $C$. zacatechichi does not affect the threshold in the MEST test in mice}

To establish whether aqueous extract of $C$. zacatechichi has the ability to prevent seizure spread through neural tissue, we used MEST test. Aqueous extract of $C$. zacatechichi administered at doses ranging from 200 to $800 \mathrm{mg} / \mathrm{kg}$ (p.o.) did not affect the MEST (Fig. 1a). 

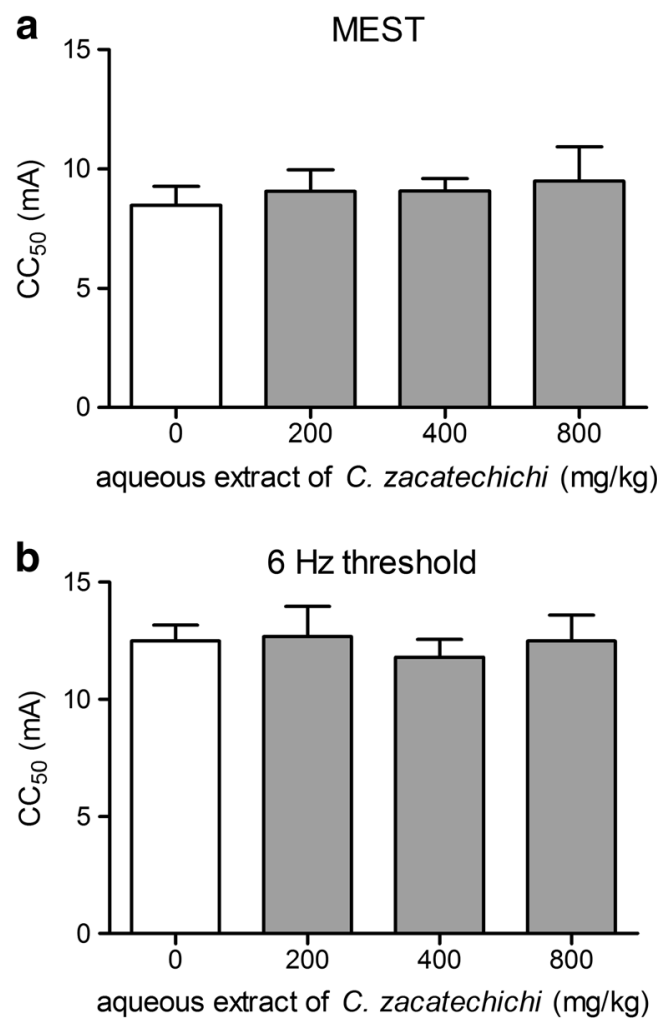

Fig. 1 Effect of the aqueous extract of C. zacatechichi $(200-800 \mathrm{mg} / \mathrm{kg}$, p.o.) on maximal electroshock seizure threshold and $6 \mathrm{~Hz}$ psychomotor seizure threshold in mice. Figure shows data for $\mathrm{CC}_{50}$ of the MEST (a) and $6 \mathrm{~Hz}$ seizure threshold (b). Data represent mean + SEM of $n=18-20$ mice for each experimental group

\section{Aqueous extract of $C$. zacatechichi does not influence the $6 \mathrm{~Hz}$ psychomotor seizure threshold in mice}

To evaluate the potential influence of aqueous extract of $C$. zacatechichi on partial psychomotor seizures, we used $6 \mathrm{~Hz}$ psychomotor seizure threshold test. As shown in Fig. 1b the aqueous extract of C. zacatechich $i$ administered at doses ranging from 200 to $800 \mathrm{mg} / \mathrm{kg}$ (p.o.) did not affect the $6 \mathrm{~Hz}$ seizure threshold.

\section{Aqueous extract of $C$. zacatechichi does not affect PTZ seizure threshold in mice}

We also investigated the influence of the aqueous extract of $C$. zacatechichi on PTZ-induced seizure threshold. The aqueous extract of C. zacatechichi administered p.o. at the doses ranging from 200 to $800 \mathrm{mg} / \mathrm{kg}$ did not alter any of the measured parameters, including myoclonic twitch (Fig. 2a), onset generalized clonus (Fig. 2b), and tonic forelimb extension (Fig. 2c). Moreover, we investigated the time course of the changes in measured parameters after a single administration of the extract ( $200 \mathrm{mg} / \mathrm{kg}$, p.o., Fig. 3). Only the tonic forelimb extension was significantly affected by the extract with the
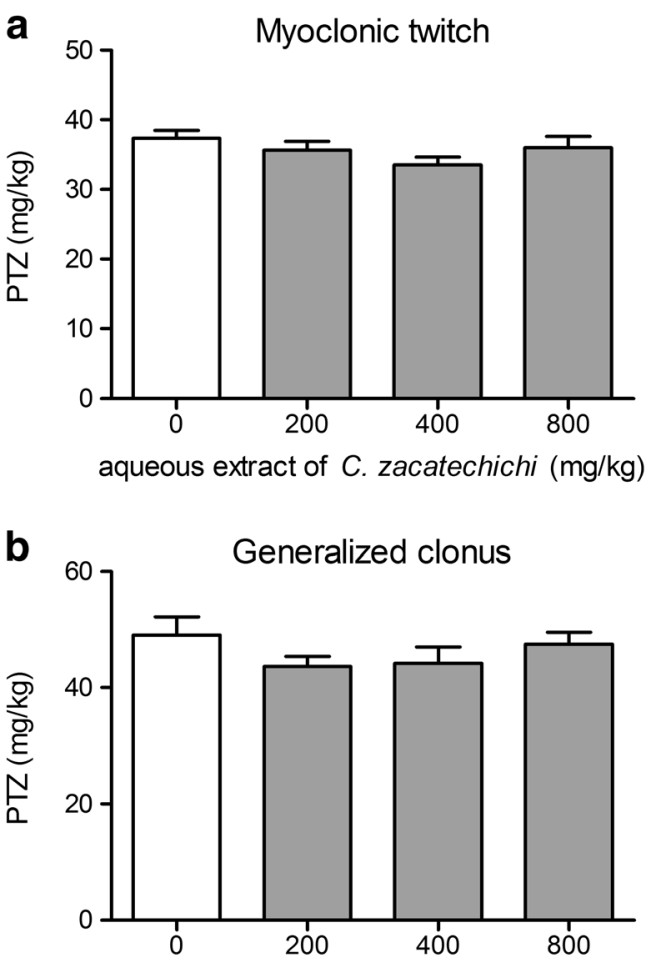

aqueous extract of $C$. zacatechichi $(\mathrm{mg} / \mathrm{kg})$

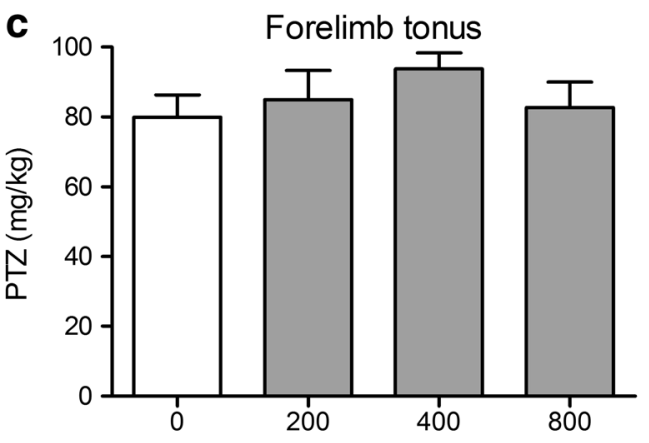

aqueous extract of C. zacatechichi $(\mathrm{mg} / \mathrm{kg})$

Fig. 2 Effect of the aqueous extract of C. zacatechichi $(200-800 \mathrm{mg} / \mathrm{kg}$, p.o.) on the pentylenetetrazole seizure threshold in mice. Figure shows data for myoclonic twitch (a), generalized clonus (b) and forelimb tonus (c). Data represent mean $+\mathrm{SEM}$ of $n=10-13$ mice for each experimental group

maximum effect observed after 60 min post administration (Fig. 3c).

\section{Aqueous extract of $\boldsymbol{C}$. zacatechichi produces depressive-like effects in the forced swim test}

In order to investigate the antidepressant-like effect of the aqueous extract of $C$. zacatechichi, we performed a forced swim test in mice. As shown in Fig. 4, the p.o. administration of the aqueous extract of C. zacatechichi at doses of 400 and 800 , but not $200 \mathrm{mg} / \mathrm{kg}$ significantly prolonged the immobility time of mice. 

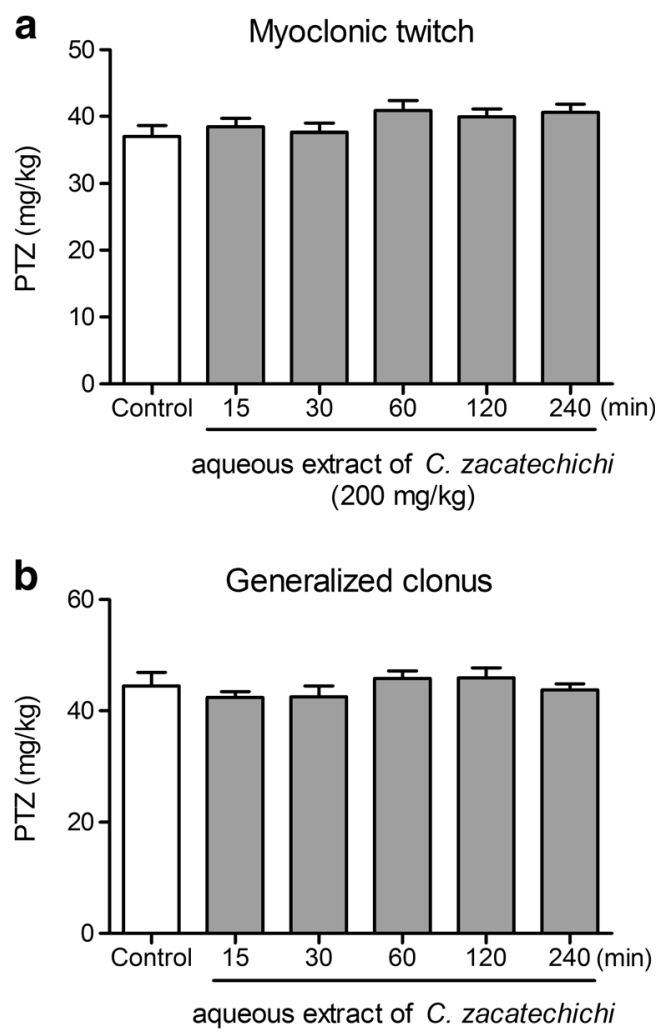

(200 mg/kg)

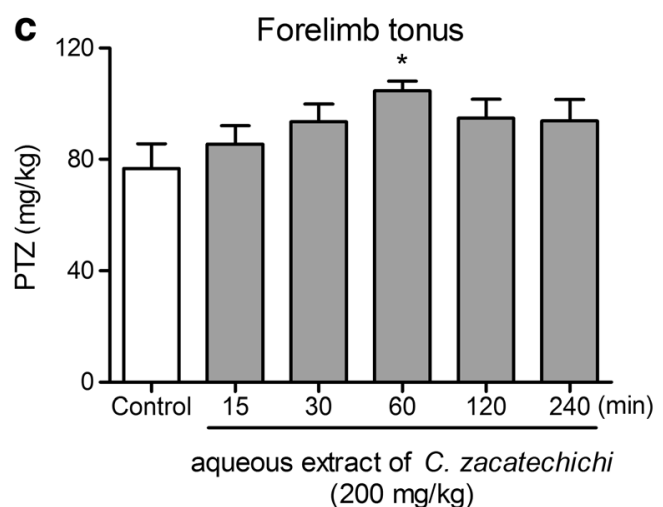

Fig. 3 The time course of the changes in pentylenetetrazole seizure threshold after a single administration of the aqueous extract of $C$. zacatechichi $(200 \mathrm{mg} / \mathrm{kg}$, p.o.). Figure shows data for myoclonic twitch (a), generalized clonus (b) and forelimb tonus (c) which is significantly increased 60 min after administration. Data represent mean + SEM of $n=10-14$ mice for each experimental group. $* P<0.05$, as compared to control

\section{Aqueous extract of $C$. zacatechichi affects neither exploratory behavior, nor anxiety levels in mice}

The influence of the p.o. administration of the aqueous extract of C. zacatechichi on mouse locomotor activity was measured over a 6 min period. The extract administered at a dose of $800 \mathrm{mg} / \mathrm{kg}$ did not modify the horizontal activity (Fig. 5).

To identify potential differences in exploratory behavior and changes in anxiogenic or anxiolytic activity after

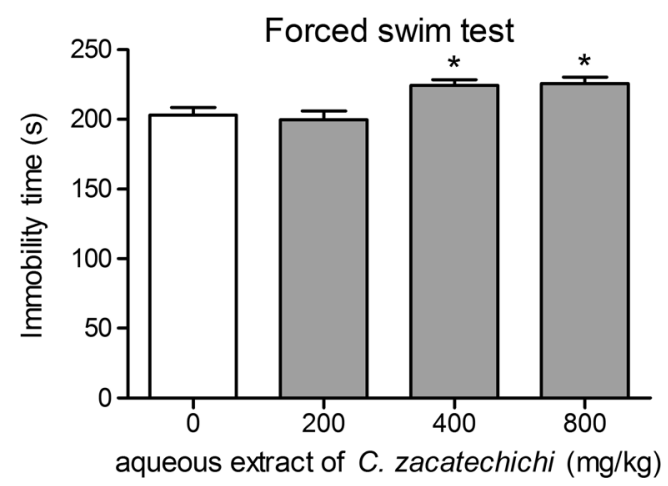

Fig. 4 Effect of the aqueous extract of C. zacatechichi $(200-800 \mathrm{mg} / \mathrm{kg}$, p.o.) on the antidepressant-like behavior in the forced swim test. Figure shows data for immobility time. Data represent mean + SEM of $n=10-12$ mice for each experimental group. $* P<0.05$ as compared to control

administration of aqueous extract of $C$. zacatechichi vs. control mice, an elevated plus-maze test was used. No significant differences were found for measures of anxiety, such as the percentage of entries (Fig. 6a) and time spent (Fig. 6b) in the open sector after p.o. administration of the extract at the dose of 400 and $800 \mathrm{mg} / \mathrm{kg}$.

\section{Aqueous extract of $C$. zacatechichi does not affect muscle strength in mice}

In order to determine the effect of aqueous extract of $C$. zacatechichi on neuromotor functions of the muscles, we used grip-strength test. The extract administered at the doses ranging from 200 to $800 \mathrm{mg} / \mathrm{kg}$, (p.o.) did not affect the grip strength in mice (Fig. 7a).

We also investigated the time course of the changes in grip strength after a single administration of the extract $(200 \mathrm{mg} /$ $\mathrm{kg}$, p.o.). There was no effect on muscle strength between control and any of the tested time points (Fig. 7b).

\section{Aqueous extract of $C$. zacatechichi does not produce CNS-mediated analgesia in mice}

To determine whether administration of aqueous extract of $C$. zacatechichi induces CNS-mediated antinociception we used hot-plate test. The extract administered at the dose of $200 \mathrm{mg} /$ $\mathrm{kg}$ (p.o.) did not affect the latencies to paw licking, rearing and escape jumping (Fig. 8a).

\section{Aqueous extract of $\boldsymbol{C}$. zacatechichi reduces visceral pain responses in mice}

In order to assess the antinociceptive activity of aqueous extract of C. zacatechichi in the periphery we used writhing test. The p.o. administration of $C$. zacatechich $i$ aqueous extract at the dose of $200 \mathrm{mg} / \mathrm{kg}$ resulted in a significant reduction of the number of writhes (Fig. 8b). 


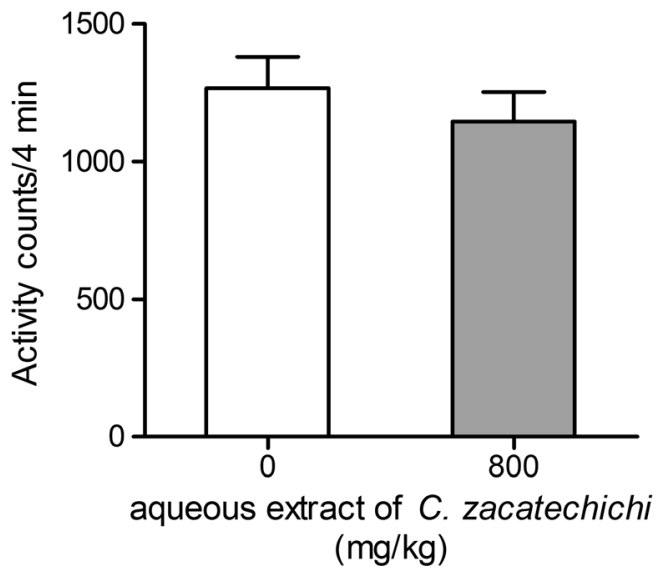

Fig. 5 Effect of the aqueous extract of C. zacatechichi $(800 \mathrm{mg} / \mathrm{kg}$, p.o.) on the locomotor activity of mice. Data represent mean + SEM of $n=11$ mice for each experimental group

\section{Chemical composition of aqueous extract of $C$. zacatechichi}

The LC-MS analysis of aqueous extract of C. zacatechichi, together with a high mass and high isotopic abundance match allowed us to obtain the most probable chemical formulas for all detected compounds. As shown in Table 1, the analysis revealed the presence of 6 constituents, which are quinic acid derivative (1), flavonol derivatives $(\mathbf{2}, \mathbf{3})$, flavone derivative (4) and germacranolides $(5,6)$; the measured accurate ion mass $[\mathrm{M}+\mathrm{H}]^{+}$of the analyzed compounds are also reported.

Alignment of obtained mass spectra with METLIN library or published papers (Chouchi and Barth 1994; Liu et al. 2012; Wu et al. 2011; Zatorski et al. 2015) resulted in the identification of following compounds: chlorogenic acid (1), rutin (2) and rutin without hydroxyl group (3), acacetin (4), calealactone C (5) and calein A (6).

\section{Discussion}

In this study we characterized the neuropharmacological and antinociceptive effects of the aqueous extract of $C$. zacatechichi in vivo. We evidenced that oral administration of the extract does not affect most of tested neurological and behavioral parameters, namely MEST, 6 Hz-induced seizure, PTZ-induced seizures, locomotor activity, plus-maze test measurements, grip strength and CNS-mediated antinociception. However, we observed significant action in the forced swim test and on one of the PTZ-induced seizures parameters, as well as significant antinociceptive effect in the model of abdominal pain.

There are several scientific reports showing beneficial actions of extracts obtained from C. zacatechichi, including antimicrobial, anti-inflammatory and anti-diarrheal effects (Bork et al. 1997; Wu et al. 2011). It has been suggested that the potential therapeutic use of $C$. zacatechichi may be hampered a

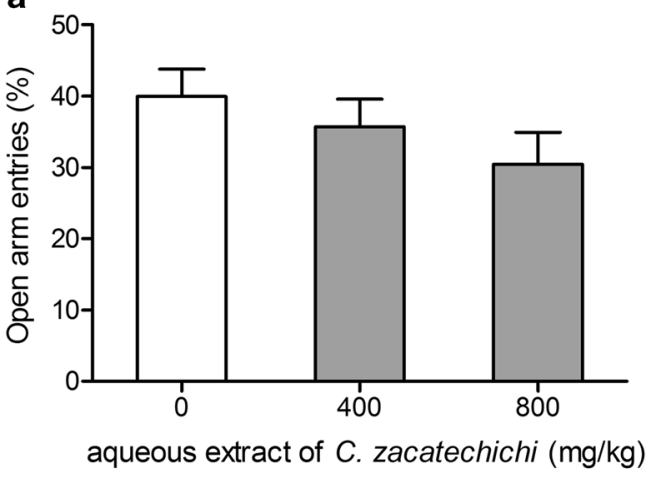

b

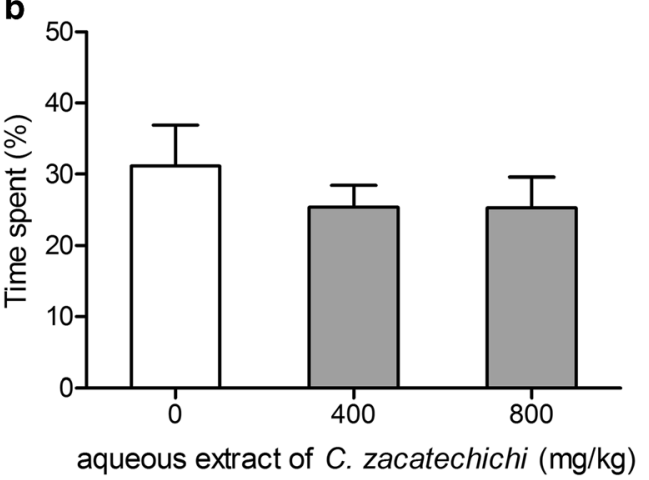

Fig. 6 Effect of the aqueous extract of C. zacatechichi (400 and $800 \mathrm{mg}$ / $\mathrm{kg}$, p.o.) on percentage of entries (a) and time spent (b) in the opened area of elevated plus-maze. Data represent mean + SEM of $n=12$ mice for each experimental group

by adverse CNS-related events and there are already some evidences in the literature for its potential psychopharmacological effects. However, these data are poorly characterized. For example, Mayagoitia et al. have shown that $C$. zacatechichi extracts increase the superficial stages of sleep and the number of spontaneous awakenings in humans (Mayagoitia et al. 1986). It was also reported that volunteers subjected to the $C$. zacatechichi extracts experienced more intense dreams during the sleep (Mayagoitia et al. 1986). Here we provide novel, relevant data, which extend the existing knowledge and show the possible negative effects of the compounds occurring in the aqueous extract of $C$. zacatechichi.

To begin with, we used three seizure models, which are broadly applied to test novel anti-convulsant drugs; namely MEST, $6 \mathrm{~Hz}$-induced seizure and PTZ-induced seizures. The aqueous extract of $C$. zacatechichi did not change any of the measured parameters, except for a slight increase in the dose of PTZ necessary to induce forelimb tonus $60 \mathrm{~min}$ after administration of the extract. Of note, this effect was not dosedependent and was present only in the time course experiment. These observations may be perceived as a virtue of the tested extract, as many hazardous, psychoactive and/or addictive compounds are known to dramatically alter PTZ convulsion threshold. For instance, (Himmel 2008) has shown that diazepam (10 mg/kg, p.o.) and morphine (10 mg/kg, i.p.) 

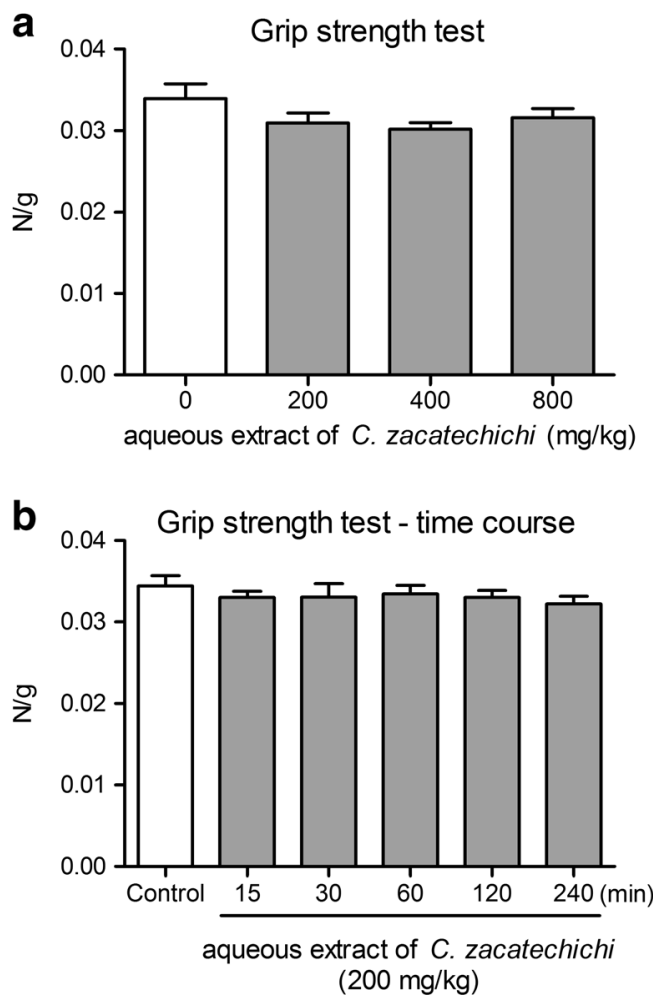

Fig. 7 The influence of the aqueous extract of C. zacatechichi on muscular strength of mice. Figure shows data for the effects on muscular strength after administration at the doses ranging from 200 to $800 \mathrm{mg} / \mathrm{kg}$, p.o. (a) and the time course of the changes in muscular strength after a single administration of the extract $(200 \mathrm{mg} / \mathrm{kg}$, p.o. (b). Data represent mean $+\mathrm{SEM}$ of $n=12$ mice for each experimental group

significantly increased PTZ convulsive threshold, while isoniazide $(120 \mathrm{mg} / \mathrm{kg}$, s.c. $)$ and yohimbine $(8 \mathrm{mg} / \mathrm{kg}$, s.c. $)$ displayed significant and reliable proconvulsive effects. On the other hand, generally safe compounds, such as caffeine and acetylsalicylic acid remained ineffective in this test.

Moreover, the aqueous extract of $C$. zacatechichi did not alter the $\mathrm{CC}_{50}$ in the MEST test, suggesting the lack of CNSrelated effects. Previously published data show that wellknown psychoactive compounds, such as amphetamine and its derivatives, cocaine and opioids typically increase seizure threshold at small doses and produce convulsions at higher ones (Bankstahl et al. 2012). The measurements of locomotor activity and several parameters in the elevated plus-maze showed changes neither in exploratory, nor in anxiety-related behaviors after administration of the aqueous extract of $C$. zacatechichi. This is in line with our previous observations, showing the lack of changes in exploratory behavior after administration of dichloromethane extract of $C$. zacatechichi in mice, especially since these two extracts contained similar groups of compounds (Sałaga et al. 2015).

The aqueous extract of C. zacatechich $i$ was inactive in the $6 \mathrm{~Hz}$ psychomotor seizure threshold test. We performed this test in a standard way, i.e., scoring motor seizure and postictal depression as total seizure response, without getting and
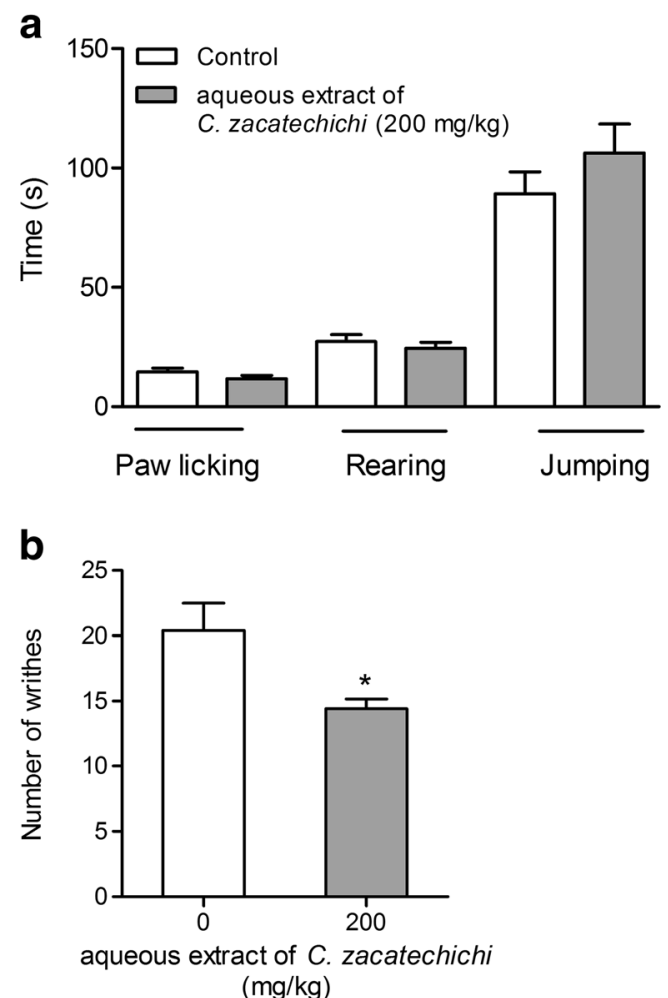

Fig. 8 The antinociceptive effect of aqueous extract of C. zacatechichi $(200 \mathrm{mg} / \mathrm{kg}$, p.o.). Figure shows data for latencies of paw licking, rearing and escape jumping in the hot-plate test (a) and number of writhes in the writhing test (b). Data represent mean + SEM of $n=12$ mice for each experimental group. ${ }^{*} P<0.05$ as compared to control

analyzing the EEG. This might be a limitation of this and other studies that utilize standard $6 \mathrm{~Hz}$ seizure test procedure because without the EEG it is not possible to distinguish the convulsive reaction from the postictal immobility, especially when testing substances that have demonstrated effects on the CNS functions (Giordano et al. 2015). The duration of postictal depression may be modulated more than the convulsive phase by centrally-active substances.

Of interest, our data showed a significant increase in the immobility time induced by two doses $(400$ and $800 \mathrm{mg} / \mathrm{kg}$, p.o.) of the aqueous extract of C. zacatechichi in a forced swim test. This observation suggests that the extract may have a depressant effect in mice tested in this paradigm. However, the effect was not dose-dependent and thus requires further investigation, preferably in other paradigms. The LC-MS analysis of the aqueous extract of C. zacatechichi revealed presence of three major groups of compounds: chlorogenic acid, acacetin (and most likely also its derivatives), rutin and rutin derivative as well as germacranolides.

Chlorogenic acid is a polyphenol and the ester of caffeic acid and quinic acid that can be found in coffee and black tea, with potential antioxidant and anti-inflammatory activities (Zatorski et al. 2015). In this study we observed that the aqueous extract of C. zacatechichi, which contains chlorogenic acid, elicited antinociceptive effect in the mouse model of abdominal pain. 
Table 1 Chemical characterization of the C. zacatechichi DCM extract

\begin{tabular}{lllll}
\hline No. & $\begin{array}{l}{ }^{\mathrm{a}}[\mathrm{M}+\mathrm{H}]^{+} \\
(\mathrm{m} / \mathrm{z})\end{array}$ & Empirical formula & Name \\
\hline 1 & ${ }^{\mathrm{a}} 355.102$ & $\mathrm{C}_{16} \mathrm{H}_{18} \mathrm{O}_{9}$ & Chlorogenic acid & Zatorski et al. 2015 \\
2 & ${ }^{\mathrm{a}} 611.161$ & $\mathrm{C}_{27} \mathrm{H}_{30} \mathrm{O}_{16}$ & Rutin & Reference standard \\
3 & ${ }^{\mathrm{a}} 595.166$ & $\mathrm{C}_{27} \mathrm{H}_{30} \mathrm{O}_{15}$ & Rutin without hydroxyl group & Reference standard \\
4 & ${ }^{\mathrm{a}} 285.076$ & $\mathrm{C}_{16} \mathrm{H}_{12} \mathrm{O}_{5}$ & Acacetin & Liu et al. 2012 \\
5 & ${ }^{\mathrm{a}} 407.170$ & $\mathrm{C}_{21} \mathrm{H}_{26} \mathrm{O}_{8}$ & Calealactone $\mathrm{C}$ & Wu et al. 2011 \\
6 & ${ }^{\mathrm{a}} 421.185$ & $\mathrm{C}_{22} \mathrm{H}_{28} \mathrm{O}_{8}$ & Calein A & Wu et al. 2011 \\
\hline
\end{tabular}

This is in line with several studies demonstrating that chlorogenic acid inhibits abdominal constrictions induced by acetic acid as well as p-benzoquinone (Chen et al. 2013; Küpeli et al. 2012; Li et al. 2009). Moreover, pure chlorogenic acid reduces pain in neuropathic pain models (Bagdas et al. 2013; Bagdas et al. 2014). One of the suggested mechanisms by which chlorogenic acid alleviates pain is inhibition of acidsensing ion channels in peripheral neurons (Qu et al. 2014). Noteworthy, chlorogenic acid does not induce antinociceptive effect in the hot-plate test. On the other hand, chlorogenic acid does not affect the CNS-related functions, such as cognitive performance and mood-related behaviour suggesting that this compound is not responsible for the depressant-like effect of the aqueous extract of $C$. zacatechichi reported in this study (Camfield et al. 2013).

Other biologically active compounds found in the extract were rutin and rutin without one hydroxyl group. Rutin is a glycoside of quercetin and rutinose occurring in buckwheat and rhubarb (Kreft et al. 1999). Rutin is a highly potent molecule due to its strong antioxidant properties. It has been shown previously that plant extracts containing high concentration of rutin as well as rutin itself induce visceral antinociception in mice (Lapa et al. 2009; Selvaraj et al. 2014). Therefore these compounds may be involved to some extent in the antinociceptive effects observed in our study. On the other hand, rutin isolated from the Schinus molle L. exhibits antidepressant-like effect in the tail suspension test without the effect on forced swim test and locomotor activity after oral administration (Machado et al. 2008). Furthermore, as shown by Dimpfel (2009), rutin and quercitin exhibit antidepressant activity in rats through inhibition of monoamine oxidase and elevation of serotonin and noradrenalin availability. Based on these reports we suggest that rutin occurring in the aqueous extract of $C$. zacatechichi should not be considered as responsible for its depressant-like effect in vivo.

On the other hand, Martínez-Vázquez et al. (2012) have recently demonstrated that the aqueous extract of Dracocephalum moldavica L. (Lamiaceae) also produce a depressant-like effect in forced swim test in mice. The chemical analysis of that extract revealed the presence of acacetin and its derivatives in high concentrations, which may be responsible for observed depressant activity (Martínez-Vázquez et al. 2012). Our analysis also showed the presence of acacetin in the aqueous extract of C. zacatechichi thus the responsibility of this compound for the increase of immobility time in the forced swim test cannot be excluded.

The last group of compounds detected by our LC-MS analysis are germacranolides, including calealactone $\mathrm{C}$ and calein A. There are only a few papers characterizing potential biological activity of germacranolides, all of which show their antimicrobial and anti-oxidative activity, but none of them assessed their activity in vivo (Umemura et al. 2008; Wu et al. 2011). This opens up a novel field for further investigations characterizing the in vivo effects of isolated germacranolides.

\section{Conclusion}

The aqueous extract of C. zacatechichi does not affect basic neurological functions or anxiety and exploratory behavior in mice after oral administration. On the other hand, it has been demonstrated in the literature that this plant preparations exhibit potent beneficial activities both in vitro and in vivo. Further chemical analyses of C. zacatechichi are thus urgently needed in order to find its all active constituents and identify which of them are responsible for the effects observed in vivo. Such findings may open up novel opportunities in design and synthesis of novel drugs.

Acknowledgments This work was supported by the Iuventus Plus program of the Polish Ministry of Science and Higher Education (\#IP2012 010772 to JF) and the Funds for Statutory Activity of Maria CurieSklodowska University, Lublin, Poland. The authors wish to thank Nina Kowalczyk for her excellent technical assistance.The study was sponsored by a Polpharma Scientific Foundation.

\section{Compliance with ethical standards}

Conflict of interest The authors declare that they have no conflict of interest. The authors alone are responsible for the content and writing of the paper. 
Open Access This article is distributed under the terms of the Creative Commons Attribution 4.0 International License (http:// creativecommons.org/licenses/by/4.0/), which permits unrestricted use, distribution, and reproduction in any medium, provided you give appropriate credit to the original author(s) and the source, provide a link to the Creative Commons license, and indicate if changes were made.

\section{References}

Bagdas D, Cinkilic N, Ozboluk HY, Ozyigit MO, Gurun MS (2013) Antihyperalgesic activity of chlorogenic acid in experimental neuropathic pain. J Nat Med 67:698-704

Bagdas D, Ozboluk HY, Cinkilic N, Gurun MS (2014) Antinociceptive effect of chlorogenic acid in rats with painful diabetic neuropathy. $\mathrm{J}$ Med Food 17:730-732

Bankstahl M, Bankstahl JP, Bloms-Funke P, Löscher W (2012) Striking differences in proconvulsant-induced alterations of seizure threshold in two rat models. Neurotoxicology 33:127-137

Barton ME, Klein BD, Wolf HH, White HS (2001) Pharmacological characterization of the $6 \mathrm{~Hz}$ psychomotor seizure model of partial epilepsy. Epilepsy Res 47:217-227

Barton ME, Peters SC, Shannon HE (2003) Comparison of the effect of glutamate receptor modulators in the $6 \mathrm{~Hz}$ and maximal electroshock seizure models. Epilepsy Res 56:17-26

Bork PM, Schmitz ML, Kuhnt M, Escher C, Heinrich M (1997) Sesquiterpene lactone containing Mexican Indian medicinal plants and pure sesquiterpene lactones as potent inhibitors of transcription factor NF-kB. FEBS Lett 402:85-90

Camfield DA, Silber BY, Scholey AB, Nolidin K, Goh A, Stough C (2013) A randomised placebo-controlled trial to differentiate the acute cognitive and mood effects of chlorogenic acid from decaffeinated coffee. PLoS One 8:e82897

Chen Z, Liao L, Zhang Z, Wu L, Wang Z (2013) Comparison of active constituents, acute toxicity, anti-nociceptive and anti-inflammatory activities of Porana sinensis Hemsl., Erycibe obtusifolia Benth. and Erycibe schmidtii Craib. J Ethnopharmacol 150:501-506

Chouchi D, Barth D (1994) Rapid identification of some coumarin derivatives in deterpenated citrus peel oil by gas chromatography. J Chromatogr A 672:177-183

Dimpfel W (2009) Rat electropharmacograms of the flavonoids rutin and quercetin in comparison to those of moclobemide and clinically used reference drugs suggest antidepressive and/or neuroprotective action. Phytomedicine 16:287-294

Eddy NB, Leimbach D (1953) Synthetic analgesics. II. Dithienylbutenyland dithienylbutylamines J Pharmacol Exp Ther 107:385-393

Giardina WJ, Gasior (2009) Acute seizure tests in epilepsy research: electroshock- and chemical-induced convulsions in the mouse. Curr Protoc Pharmacol 45:5.22.1-5.22.37

Giordano C, Vinet J, Curia G, Biagini G (2015) Repeated 6-Hz corneal stimulation progressively increases $\mathrm{FosB} / \Delta \mathrm{FosB}$ levels in the lateral amygdala and induces seizure generalization to the hippocampus. PLoS One 10:e141221

Himmel HM (2008) Safety pharmacology assessment of central nervous system function in juvenile and adult rats: effects of pharmacological reference compounds. J Pharmacol Toxicol Methods 58:129-146

Kimball AW, Burnett Jr WT, Doherty DG (1957) Chemical protection against ionizing radiation. I. Sampling methods for screening compounds in radiation protection studies with mice. Radiat Res 7:1-12

Kreft S, Knapp M, Kreft I (1999) Extraction of rutin from buckwheat (Fagopyrum esculentum Moench) seeds and determination by capillary electrophoresis. J Agric Food Chem 47:4649-4652

Küpeli AE, Bahadir AÖ, Süntar I, Ergene B, Saltan ÇG (2012) Ethnopharmacological evaluation of some Scorzonera species: in vivo anti-inflammatory and antinociceptive effects. J Ethnopharmacol 140:261-270

Laird JM, Martinez-Caro L, Garcia-Nicas E, Cervero F (2001) A new model of visceral pain and referred hyperalgesia in the mouse. Pain 92:335-342

Lapa FR, Gadotti VM, Missau FC, Pizzolatti MG, Marques MC, Dafré AL, Farina M, Rodrigues AL, Santos AR (2009) Antinociceptive properties of the hydroalcoholic extract and the flavonoid rutin obtained from Polygala paniculata L. in mice. Basic Clin Pharmacol Toxicol 104:306-315

Leonti M, Sticher O, Heinrich M (2003) Antiquity of medicinal plant usage in two macro-mayan ethnic groups (México). J Ethnopharmacol 88:119-124

Li X, Yang YB, Yang Q, Sun LN, Chen WS (2009) Anti-inflammatory and analgesic activities of Chaenomeles speciosa fractions in laboratory animals. J Med Food 12:1016-1022

Lister RG (1987) The use of a plus-maze to measure anxiety in the mouse. Psychopharmacology (Berl) 92:180-185

Liu J, Chen L, Cai S, Wang Q (2012) Semisynthesis of apigenin and acacetin-7-O- $\beta$-D-glycosides from naringin and their cytotoxic activities. Carbohydr Res 357:41-46

Machado DG, Bettio LE, Cunha MP, Santos AR, Pizzolatti MG, Brighente IM, Rodrigues AL (2008) Antidepressant-like effect of rutin isolated from the ethanolic extract from Schinus molle L. in mice: evidence for the involvement of the serotonergic and noradrenergic systems. Eur J Pharmacol 587:163-168

Martínez-Vázquez M, Estrada-Reyes R, Martínez-Laurrabaquio A, López-Rubalcava C, Heinze G (2012) Neuropharmacological study of Dracocephalum moldavica L. (Lamiaceae) in mice: sedative effect and chemical analysis of an aqueous extract. J Ethnopharmacol 141:908-917

Mayagoitia L, Díaz JL, Contreras CM (1986) Psychopharmacologic analysis of an alleged oneirogenic plant: Calea zacatechichi. J Ethnopharmacol 18:229-243

Nieoczym D, Łuszczki JJ, Czuczwar SJ, Wlaź P (2010) Effect of sildenafil on the anticonvulsant action of classical and second-generation antiepileptic drugs in maximal electroshock-induced seizures in mice. Epilepsia 51:1552-1559

Porsolt RD, Bertin A, Jalfre M (1977) Behavioral despair in mice: a primary screening test for antidepressants. Arch Int Pharmacodyn Ther 229:327-336

Qu ZW, Liu TT, Qiu CY, Li JD, Hu WP (2014) Inhibition of acid-sensing ion channels by chlorogenic acid in rat dorsal root ganglion neurons. Neurosci Lett 567:35-39

Sałaga M, Kowalczuk A, Zielińska M, Błażewicz A, Fichna J (2015) Calea zacatechichi dichloromethane extract exhibits antidiarrheal and antinociceptive effects in mouse models mimicking irritable bowel syndrome. Naunyn Schmiedeberg's Arch Pharmacol 388:1069-1077

Sałaga M, Polepally PR, Sobczak M, Grzywacz D, Kamysz W, Sibaev A, Storr M, Do Rego JC, Zjawiony JK, Fichna J (2014) Novel orally available salvinorin A analog PR-38 inhibits gastrointestinal motility and reduces abdominal pain in mouse models mimicking irritable bowel syndrome. J Pharmacol Exp Ther 350:69-78

Selvaraj G, Kaliamurthi S, Thirungnasambandam R, Vivekanandan L, Balasubramanian T (2014) Anti-nociceptive effect in mice of thillai flavonoid rutin. Biomed Environ Sci 27:295-299

Sobczak M, Pilarczyk A, Jonakowski M, Jarmuż A, Sałaga M, Lipkowski AW, Fichna J (2014) Anti-inflammatory and antinociceptive action of the dimeric enkephalin peptide biphalin in the mouse model of colitis: new potential treatment of abdominal pain associated with inflammatory bowel diseases. Peptides 60:102-106

Umemura K, Itoh T, Hamada N, Fujita Y, Akao Y, Nozawa Y, Matsuura $\mathrm{N}$, Iinuma M, Ito $\mathrm{M}$ (2008) Preconditioning by sesquiterpene lactone enhances $\mathrm{H}_{2} \mathrm{O}_{2}$-induced $\mathrm{Nrf2} / \mathrm{ARE}$ activation. Biochem Biophys Res Commun 368:948-954 
Venegas-Flores H, Segura-Cobos D, Vázquez-Cruz B (2002) Antiinflammatory activity of the aqueous extract of Calea zacatechichi. Proc West Pharmacol Soc 45:110-111

Wu H, Fronczek FR, Burandt Jr CL, Zjawiony JK (2011) Antileishmanial germacranolides from Calea zacatechichi. Planta Med 77:749-753
Zatorski H, Sałaga M, Zielińska M, Piechota-Polańczyk A, Owczarek K, Kordek R, Lewandowska U, Chen C, Fichna J (2015) Experimental colitis in mice is attenuated by topical administration of chlorogenic acid. Naunyn Schmiedeberg's Arch Pharmacol 388:643-651 